\title{
Sticky-information in forming inflation expectations
}

\author{
Wenyu Liư', 2 \\ ${ }^{1}$ China United Network Communications Group Company Limited, Beijing 100033, China \\ ${ }^{2}$ Beijing University of Posts and Telecommunications, Beijing 100876, China
}

\begin{abstract}
Inflation expectation plays an important role in macro-economy, and the stickiness of information is critical for the management of inflation expectations. This paper tries to provide supportive evidence of sticky-information in forming inflation expectations in three significant economies, i.e., China, Eurozone, and the United States. Based on the epidemiology model, our results show that the stickiness in China is smaller than that in Eurozone and the United States. (JEL: E31, E52, E58, D84)
\end{abstract}

Keywords: Inflation expectations; Information update frequency; Heterogeneity.

\section{Introduction}

There is a rapidly growing literature on sticky-information, indicating that agents update information occasionally rather than instantaneously. The sticky-information models are proved to be effective in solving some puzzles of inflation and unemployment (e.g. Mankiw and Reis, 2010). However, the sticky-information across major economies seems to be ignored.

In the research of sticky-information model, Mankiw and Reis (2001) propose a Sticky Information Phillips Curve (SIPC) based on the hypothesis of imperfect information. Further investigations (Mankiw et al., 2003; Mankiw and Reis, 2010) demonstrate the extensive stickyinformation in goods, labor, and financial markets. Moreover, Carroll (2003) proposes an epidemiology model which justifies that information diffuses slowly throughout consumers and they update inflation expectations occasionally. The stickiness of information of U.S. in forming inflation expectations is estimated for the first time. Since then, the sticky-information model is widely investigated. The stickiness of several other regions is estimated (Nunes, 2009; Reid, 2015). Furthermore, some focus is put on the stickiness of different regions. Dovern and Doepke (2008) extend the epidemiology model to four European economies (France, Germany, Italy, and U.K.) and demonstrate different stickiness. Khan and Zhu (2002) investigate U.S., Canada, and U.K. Xu et al. (2017) note structural changes in the state-dependence and time-trend of information stickiness in the United States and Eurozone. More studies, e.g. Handjiyska (2004), Gomes (2012), and Wieland (2014) provide supportive evidence for the sticky-information. However, Kiley (2007) maintains that the sticky-price model fits the economy better than the sticky-information model once hybrid-behavior is allowed.

Although the sticky-information seems to be effective in many countries, corresponding evidence for China is still lacking, and the regional difference of stickiness seems to be insufficiently studied.

This paper tries to provide supportive evidence of the heterogeneous sticky-information in three significant economies. The rest of the paper is organized as follows. Section 2 describes data and model. Section 3 presents some priori tests. Section 4 estimates and compares the stickiness in China, the United States, and Eurozone. Section 5 is a summary of the paper.

\section{Data and Model}

\subsection{Data}

The Household Savings Survey System of the People's Bank of China provides urban residents' attitude towards the current price and expectations of price in the future since 1995. While the survey in Eurozone asks respondents about their inflation expectations for the next 12 months. The Livingston Survey in U.S. asks respondents to state their precise quantitative inflation expectations. 
The internationally accepted Probability Method is adopted to calculate quantitative inflation expectation in China and Eurozone.
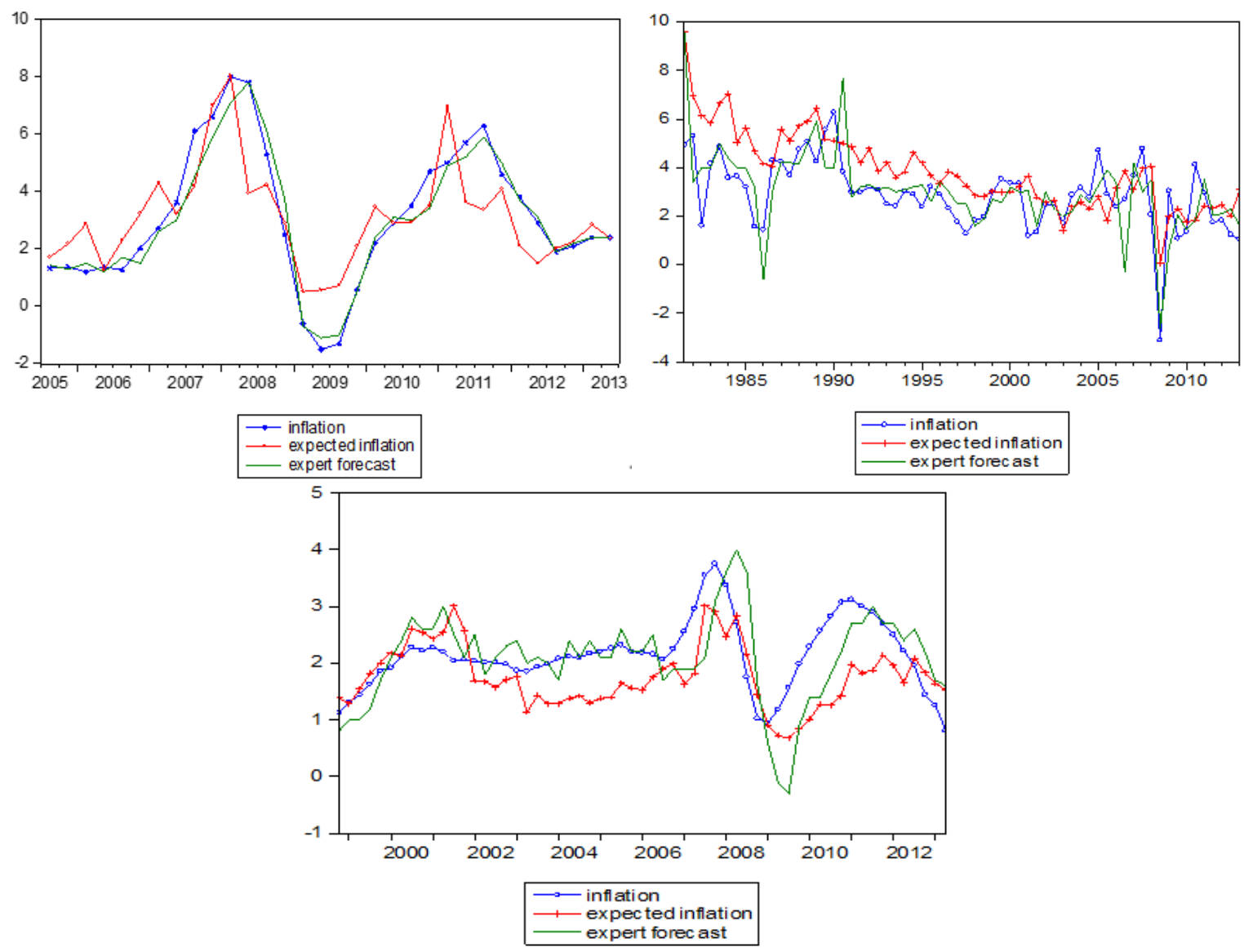

Figure 1. Inflation, expectations of experts and households in China (left), the United States (middle), and Eurozone (right).

Figure 1 compares the inflation, expectations of experts and households in China, the United States, and Eurozone. According to the three figures, the expectations of experts and households are close to the inflation generally. However, the gaps between two expectations and inflation are apparent sometimes. Specifically, the expert expectation in China is extremely close to the real inflation while the other two districts are not; the households' expectation is much higher than that of experts before 1999 in the United States and inclines relatively less after 1999; however, households' expectation in Eurozone varies significantly from experts.

\subsection{The epidemiology model}

The epidemiology model proposed by Carroll (2003) is viewed as a micro foundation model of inflation expectations. Only $\lambda$ percent of households get new information and update their inflation expectations based on the latest information, and the remaining $1-\lambda$ percent of households continue to use inflation expectations based on outdated information. Therefore, the inflation expectation generates as follows.

$$
E_{t}^{H H} \pi_{t, t+1}=\lambda E_{t}^{E X} \pi_{t, t+1}+(1-\lambda) E_{t-1}^{H H} \pi_{t, t+1}
$$

Where $E_{t}^{H H} \pi_{t, t+1}$ and $E_{t}^{E X} \pi_{t, t+1}$ are the inflation expectations for $t+1$ of the households and experts respectively, $\lambda$ is the information update frequency mathematically, and $1-\lambda$ represents the stickiness of information. 


\section{Priori Tests}

Before the estimation of the stickiness of information, some priori investigations of the expectations of experts and households are necessary. Three performance prediction indicators MAE (Mean Absolute Error), RMSE (Root Mean Square Error) and TUI (Theil Inequality Coefficient) are adopted to measure the bias between expectations and inflation. The detailed results of the three indicators are summarized in Table 1.

Table 1. Comparison of expert expectation and public expectation.

\begin{tabular}{ccccccc}
\hline & \multicolumn{2}{c}{ China } & \multicolumn{2}{c}{ United States } & \multicolumn{2}{c}{ Eurozone } \\
Index & $2005 Q 3-2018 Q 2$ & \multicolumn{2}{c}{ 1981/12-2018/6 } & \multicolumn{2}{c}{ 1998Q4-2018Q2 } \\
& Experts & Households & Experts & Households & Experts & Households \\
\hline MAE & 0.0152 & 0.8000 & 0.7833 & 1.0868 & 0.4937 & 0.5900 \\
RASE & 0.0346 & 1.0415 & 1.1209 & 1.2977 & 0.6572 & 0.7063 \\
TUI & 0.0106 & 0.3184 & 0.4037 & 0.4675 & 0.2954 & 0.3175 \\
\hline
\end{tabular}

Note: MAE is the mean absolute error between expectations and real inflation, RMSE is the root mean square error of inflation expectation, TUI is the Theil inequality coefficient.

From Table 1, the expectations of experts are apparently more precise than that of households wherever in China, the United States, or Eurozone. More specifically, in the United States and Eurozone, the RMSE of experts' expectation is 7\%-28\% lower than households, indicating that the expectations of experts are closer to inflation compared to households. The deviation is expanded in China. The conclusion that experts' expectations are more accurate than that of households is consistent with the basic requirements of epidemiology model, indicating that at least part of households reference experts' expectations when forming individual expectation. The above conclusion provides certain priori supporting evidence for our investigation.

The epidemiology model believes that experts' expectation is an important causation of households' inflation expectation. Therefore, the causality between experts' expectation and households' expectation is examined before the estimation of the stickiness of information. The results of the Granger tests are summarized in Table 2.

Table 2. Granger causality test.

\begin{tabular}{|c|c|c|c|c|c|c|}
\hline \multirow{2}{*}{ Null Hypothesis: } & \multicolumn{2}{|c|}{ China } & \multicolumn{2}{|c|}{ United States } & \multicolumn{2}{|c|}{ Eurozone } \\
\hline & F-Statistic & Prob & F-Statistic & Prob & F-Statistic & Prob \\
\hline$\pi^{\mathrm{EX}}$ does $\mathrm{r}$ & 145.31 & 0.00 & 2.10 & 0.09 & 3.60 & 0.02 \\
\hline$\pi^{\mathrm{HH}}$ does not Granger Cause $\pi^{\mathrm{EX}}$ & 1.94 & 0.16 & 4.44 & 0.02 & 2.33 & 0.09 \\
\hline
\end{tabular}

According to Table2, the null hypothesis that "experts' expectation does not Granger cause households' expectation" is rejected at the significance level of $10 \%$ in three districts. The result fully demonstrates that experts' expectation is a significant causation of households' expectation. On the other hand, the null hypothesis of "households' expectation does not Granger cause experts' expectation" is rejected both in the United States and Eurozone, indicating that, in addition to China, households' expectation is also the Granger causation of experts' expectation. Therefore, experts' expectation is a causation of households' expectation.

\section{Sticky-information}

Above investigation provides transcendental supporting evidence for the epidemiology model. This section estimates and compares the stickiness of information in China, the United States, and Eurozone based on the epidemiology model. 


\subsection{Research on individual districts}

The three districts are tremendously different in economic developments and national identities. Research districts specifically is of great significance to capture the characteristics of information update frequency and the causation of heterogeneous inflation expectations.

The questionnaire in China is conducted once a quarter and investigates the inflation of next quarter, the United States conduct relevant survey twice a year and investigates the inflation of the following 6 months. However, the survey is conducted once a quarter in Eurozone and investigates the inflation of the following 12 months. The empirical model for China and the United States is equation (2), and empirical model for Eurozone is equation (3).

$$
\begin{gathered}
E_{t}^{H H} \pi_{t, t+1}=\lambda_{0}+\lambda_{1} E_{t}^{E X} \pi_{t, t+1}+\lambda_{2} E_{t-1}^{H H} \pi_{t, t+1}+\lambda_{3} \pi_{t-2, t-1}+\varepsilon_{t} \\
E_{t}^{H H} \pi_{t, t+4}=\lambda_{0}+\lambda_{1} E_{t}^{E X} \pi_{t, t+4}+\lambda_{2} E_{t-1}^{H H} \pi_{t-1, t+3}+\lambda_{3} \pi_{t-5, t-1}+\varepsilon_{t}
\end{gathered}
$$

Where $\pi$ is the inflation, and other notations are the same as above. Estimate equations (2) and (3) under different restrictions. The estimation results are summarized in Table3.

\begin{tabular}{|c|c|c|c|c|c|}
\hline China & $\lambda_{0}$ & $\lambda_{1}$ & $\lambda_{2}$ & $\lambda_{3}$ & $\begin{array}{c}\text { Test } \\
\text { P-value }\end{array}$ \\
\hline M1 & & $\begin{array}{c}0.52^{* * *} \\
(0.0458)\end{array}$ & $\begin{array}{r}0.47^{* * *} \\
(0.0\end{array}$ & 489) & $\begin{array}{c}\lambda_{1}+\lambda_{2}=1 \\
0.9921\end{array}$ \\
\hline M2 & & $\begin{array}{c}0.52^{* * *} \\
(0.0443)\end{array}$ & $\begin{array}{r}0.47^{* * *} \\
(0.0\end{array}$ & 481) & $\begin{array}{c}\lambda_{1}=0 \\
0.0000\end{array}$ \\
\hline M3 & $\begin{array}{c}-0.37^{* * *} \\
(0.1267)\end{array}$ & $\begin{array}{c}0.57^{* * *} \\
(0.0380)\end{array}$ & $\begin{array}{c}0.51^{* * *} \\
(0.0394)\end{array}$ & & $\begin{array}{c}\lambda_{0}=0 \\
0.0070\end{array}$ \\
\hline M4 & & $\begin{array}{c}0.41^{* * *} \\
(0.0271)\end{array}$ & $\begin{array}{c}0.83^{* * *} \\
(0.0649)\end{array}$ & $\begin{array}{l}-0.25^{* * *} \\
(0.0435)\end{array}$ & $\begin{array}{c}\sum_{\mathrm{i}=1}^{3} \lambda_{\mathrm{i}}=1 \\
0.4912\end{array}$ \\
\hline M5 & $\begin{array}{c}-0.16^{* * *} \\
(0.1302)\end{array}$ & $\begin{array}{c}0.47^{* * *} \\
(0.0503)\end{array}$ & $\begin{array}{c}0.74^{* * *} \\
(0.0975)\end{array}$ & $\begin{array}{l}-0.18^{* * *} \\
(0.0750)\end{array}$ & $\begin{array}{c}\lambda_{3}=0 \\
0.0260\end{array}$ \\
\hline M6 & & & $\begin{array}{c}1.51^{* * *} \\
(0.1412)\end{array}$ & $\begin{array}{c}-0.57^{* * *} \\
(0.1332)\end{array}$ & $\begin{array}{c}\lambda_{2}+\lambda_{3}=1 \\
0.2552\end{array}$ \\
\hline Eurozone & $\lambda_{0}$ & $\lambda_{1}$ & $\lambda_{2}$ & $\lambda_{3}$ & $\begin{array}{c}\text { Test } \\
\text { P-value }\end{array}$ \\
\hline M1 & & $\begin{array}{c}0.23^{* * *} \\
(0.0703)\end{array}$ & $\begin{array}{r}0.72^{* * *} \\
(0.0\end{array}$ & & $\begin{array}{c}\lambda_{1}+\lambda_{2}=1 \\
0.0336\end{array}$ \\
\hline M2 & & $\begin{array}{c}0.16^{* *} \\
(0.0637)\end{array}$ & $\begin{array}{r}0.84^{* *} \\
(0.0\end{array}$ & 789) & $\begin{array}{c}\lambda_{1}=0 \\
0.0172\end{array}$ \\
\hline M3 & $\begin{array}{c}0.25^{*} \\
(0.1386)\end{array}$ & $\begin{array}{c}0.20^{* * *} \\
(0.0706)\end{array}$ & $\begin{array}{c}0.62^{* * *} \\
(0.0993)\end{array}$ & & $\begin{array}{c}\lambda_{0}=0 \\
0.0765\end{array}$ \\
\hline M4 & & $\begin{array}{c}0.27^{* * *} \\
(0.0729)\end{array}$ & $\begin{array}{c}0.64^{* * *} \\
(0.1066)\end{array}$ & $\begin{array}{c}0.01 \\
(0.0468)\end{array}$ & $\begin{array}{c}\sum_{\mathrm{i}=1}^{3} \lambda_{\mathrm{i}}=1 \\
0.0070\end{array}$ \\
\hline M5 & $\begin{array}{c}0.47^{*} \\
(0.2526)\end{array}$ & $\begin{array}{c}0.19^{* *} \\
(0.0835)\end{array}$ & $\begin{array}{c}0.63^{* * *} \\
(0.1041)\end{array}$ & $\begin{array}{c}-0.11 \\
(0.0803)\end{array}$ & $\begin{array}{c}\lambda_{3}=0 \\
0.1765\end{array}$ \\
\hline M6 & & & $0.97^{* * *}$ & 0.00 & $\lambda_{2}+\lambda_{3}=1$ \\
\hline
\end{tabular}

Table 3. Information update frequencies of three districts. 


\begin{tabular}{cccccc} 
& & & $(0.0636)$ & $(0.0523)$ & 0.3669 \\
\hline \multirow{2}{*}{ United States } & $\lambda_{0}$ & $\lambda_{1}$ & $\lambda_{2}$ & $\lambda_{3}$ & $\begin{array}{c}\text { Test } \\
\text { P-value }\end{array}$ \\
& & & $0.34^{* * *}$ & $0.71^{* * *}$ & $\lambda_{1}+\lambda_{2}=1$ \\
M1 & & $(0.0575)$ & $(0.0453)$ & 0.0174 \\
& & $0.31^{* * *}$ & $0.69^{* * *}$ & $\lambda_{1}=0$ \\
M2 & & $(0.0489)$ & $(0.0419)$ & 0.0000 \\
& 0.13 & $0.32^{* * *}$ & $0.69^{* * *}$ & & $\lambda_{0}=0$ \\
M3 & $(0.1851)$ & $(0.0615)$ & $(0.0532)$ & & 0.4898 \\
& & $0.32^{* * *}$ & $0.69^{* * *}$ & -0.25 & $\sum_{\mathrm{i}=1}^{3} \lambda_{\mathrm{i}}=1$ \\
M4 & & $(0.0605)$ & $(0.0676)$ & $(0.0464)$ & 0.0175 \\
M5 & 0.05 & $0.32^{* * *}$ & $0.69^{* * *}$ & 0.06 & $\lambda_{3}=0$ \\
& $(0.2068)$ & $(0.0635)$ & $(0.0714)$ & $(0.0645)$ & 0.5205 \\
M6 & & & $0.92^{* * *}$ & 0.06 & $\lambda_{2}+\lambda_{3}=1$ \\
& & & $(0.0628)$ & $(0.0767)$ & 0.6725 \\
\hline
\end{tabular}

Note: $* * *, * *, *$ denote significance at $1 \%, 5 \%, 10 \%$ level respectively. The first four columns are the point estimations of $\lambda$ and corresponding standard deviations; the last column is the results and Pvalues of some tests.

According to Table 3, we get the following analysis. For M1, we estimate the following models under no restrictions: $E_{t}^{H H} \pi_{t, t+1}=\lambda_{1} E_{t}^{E X} \pi_{t, t+1}+\lambda_{2} E_{t-1}^{H H} \pi_{t, t+1}+\varepsilon_{t}$ (for China and the United States) and $E_{t}^{H H} \pi_{t, t+4}=\lambda_{1} E_{t}^{E X} \pi_{t, t+4}+\lambda_{2} E_{t-1}^{H H} \pi_{t-1, t+3}+\varepsilon_{t}$ (for Eurozone). According to Table 3, the estimated $\lambda_{1}$ are statistically significant in three districts and the constraints of epidemiology model $\lambda_{1}+\lambda_{2}=1$ is satisfied in China under $99 \%$ confidence level. The result indicates the proportion of households forming inflation expectations referencing expert expectations and those based on out-oftime information add up to $100 \%$. Although the United States and Eurozone do not satisfy the constraints statistically, the sums of $\lambda_{1}$ and $\lambda_{2}$ are 0.95 and 1.05 respectively, which are very close to 1 .

The estimated $\lambda_{1}$ in China is 0.52 . On the one hand, $\lambda_{1}=0.52$ illustrates $52 \%$ of households in China update information related to inflation and form new expectations based on the latest information each quarter, indicating that the integrated update frequency is 6 months on average. One the other hand, it illustrates that $5 \%$ of households use information outdated more than one year to form inflation expectations. Although $95 \%$ of households use information within one year to form inflation expectations, according to Mankiw and Reis (2001), the macro economy status will be significantly different to when all the households update information completely and immediately. The estimated $\lambda_{1}$ in Eurozone is 0.23 indicating that $23 \%$ of households update information each quarter and the estimated $\lambda_{1}$ in the United States is 0.34 indicating that $34 \%$ of the United States' households update inflation every half year.

For M2 we re-estimate above models under the restrictions of $\lambda_{1}+\lambda_{2}=1, \lambda_{1}$ in three districts change little and all of three are statistically significant. Besides, the estimated parameters of M2 are quite close to M1 especially in China. The estimates demonstrate the good robustness and reliability of M1. For M3-M6, newspapers, televisions or other new mediums are good channels for the public to get new information, and they are represented by the factor of expert expectation in epidemiology model. However, some people may form inflation expectations based on the current and previous inflation. This channel is characterized by adding lagged inflation in the models.

The estimation results of China indicate that $\lambda_{3}$ are statistically significant in M4-M6, but the signs are negative which illustrates that expectation lowers if the past inflation is higher, which misrepresents the facts. Further tests find a serious multicollinearity between past inflation, expert 
expectation, and household expectation. Therefore, the significance is more likely to be affected by multicollinearity. With the addition of inflation and the constant term, $\lambda_{1}$ changes little while $\lambda_{2}$ changes a lot. Furthermore, the SC of M3 rises a little after adding the constant term indicating that the constant term is not necessary. Combining above analysis, estimation results of M1 is optimal for China in capturing the formation of inflation expectations. And the estimated $\lambda_{1}$ captures information update ratio accurately, while $\lambda_{2}$ is the total percentage of households maintaining old inflation expectations and those forming expectations based on past inflation, rather than the percentage of households maintaining old expectations only.

For Eurozone and the United States, $\lambda_{3}$ in all models are not significant. The constant term in M3 of the United States is not significant, and the adjusted- $\mathrm{R}^{2}$ in Eurozone drops when adding constant term into M3. Therefore, for the United States and Eurozone, M1 is the optimal.

The primary conclusions of the research are summarized as follows. First, the average information update frequency in China is once every 6 months, while Eurozone is once every 13 months and the United States is 18 months; nearly $5 \%$ of Chinese households use at least one-year outdated information, and the proportion in Eurozone and the United States are 35\% and $43 \%$ respectively. Compared to the research result of 12 months (Carroll, 2003), the update frequency in the United States estimated in this paper is lower. After the recession of 1990, the fluctuation of inflation is highly reduced than before in the United States. And the inflation is controlled with the high-speed economic development. With lower inflation deviation and comparatively low inflation rate, inflation is worthy of less concern for households, and the United States prefer to spend money and time on other activities instead of updating information and inflation expectation considering the high cost of collecting information and optimizing inflation expectation. Therefore, the information update frequency is lower. Compared to the United States (1.44) and Eurozone (0.61), the standard deviation of inflation is much higher in China (2.14), therefore, it is not surprising that the update frequency in China is apparently higher than the United States and Eurozone. The estimated $\lambda_{1}$ in Eurozone is close to 0.17 which Doepke (2008) get in investigating four European countries (Germany, Britain, France, and Italy), demonstrating the relatively low information update frequency in Eurozone. Coincidentally, the inflation in Eurozone drops in 2002 and the new monetary policy aiming to stabilize inflation is introduced in the same year. In consequence, the uncertainty of inflation in Eurozone is effectively reduced and the motivation to update information is reduced, which decrease the information transmission speed. However, with the emergence and spread of the subprime mortgage crisis, the global financial and economic markets are mauled, especially the Eurozone. Therefore, the higher information update frequency is in line with the real economic condition.

Second, households in China have significant back-looking behavior in forming inflation expectations while the United States and European are not. In the study of Carroll (2003), the inflation is statistically significant with a negative sign, which is like our research of China. There is still a certain household forming inflation expectations based on the past inflation rather than the latest information. The estimated $\lambda_{3}$ of the United States and Eurozone are statistically insignificant indicating little back-looking behaviors.

\subsection{Integrated study of three districts}

For further study, we compare information update frequencies in China, the United States, and Eurozone in the same time frame through a panel model (4). To make the results more comparable, we adjust the United States data to quarterly data. We further limit the coefficients of the three districts stay the same, and SUR is adopted to estimate the model. The estimation results of hybrid model are summarized in Table 4:

$$
E_{i t}^{H H} \pi_{i t, t+1}=\lambda_{i 0}+\lambda_{i 1} E_{i t}^{E X} \pi_{i t, t+1}+\lambda_{i 2} E_{i t-1}^{H H} \pi_{i t, t+1}+\lambda_{i 3} \pi_{i t-2, t-1}+\varepsilon_{i t}
$$

Where $i$ denotes different districts. 
Table 4. Panel study.

\begin{tabular}{cccccc}
\hline & $\lambda_{0}$ & $\lambda_{1}$ & $\lambda_{2}$ & $\lambda_{3}$ & $\begin{array}{c}\text { Test } \\
\text { P-value }\end{array}$ \\
\hline \multirow{2}{*}{ M1 } & & $0.39^{* * *}$ & $0.58^{* * *}$ & & $\lambda_{1}+\lambda_{2}=1$ \\
& & $(0.0357)$ & $(0.0393)$ & & 0.2919 \\
M2 & -0.02 & $0.39^{* * *}$ & $0.60^{* * *}$ & & $\lambda_{0}=0$ \\
& $(0.0997)$ & $(0.0379)$ & $(0.0445)$ & & 0.8164 \\
M3 & & $0.39^{* * *}$ & $0.78^{* * *}$ & -0.17 & $\sum_{\mathrm{i}=1}^{3} \lambda_{\mathrm{i}}=1$ \\
& & $(0.0357)$ & $(0.0666)$ & $(0.0466)$ & 0.8940 \\
M4 & $0.19^{* * *}$ & $0.36^{* * *}$ & $0.78^{* * *}$ & $-0.20^{* * *}$ & $\lambda_{3}=0$ \\
& $(0.1011)$ & $(0.0375)$ & $(0.0652)$ & $(0.0494)$ & 0.0001 \\
M5 & & & $1.11^{* * *}$ & $-0.15^{* * *}$ & $\lambda_{2}+\lambda_{3}=1$ \\
& & & $(0.0669)$ & $(0.0571)$ & 0.2036 \\
\hline
\end{tabular}

Note: $* * * * * *$ denote significance at $1 \%, 5 \%, 10 \%$ level respectively. The first four columns are the point estimations of $\lambda$ and corresponding standard deviations; the last column is the results and Pvalues of some tests.

For $\mathrm{M} 1$, we estimate the following model under no restrictions: $E_{i t}^{H H} \pi_{i t, t+1}=$ $\lambda_{i 1} E_{i t}^{E X} \pi_{i t, t+1}+\lambda_{i 2} E_{i t-1}^{H H} \pi_{i t, t+1}+\varepsilon_{i t} . \lambda_{1}=0.39, \lambda_{2}=0.58$ And both are significant under $99 \%$ confidence level. Furthermore, the estimation results satisfy the restrictive conditions of $\lambda_{1}+\lambda_{2}=1$. For M2, the addition of the constant term $\lambda_{0}$ make little change to $\lambda_{1}$ and $\lambda_{2}$, and $\lambda_{0}$ is insignificant. For M3-M5, add the constant term and inflation separately, and $\lambda_{3}$ is statistically significant but negative. Furthermore, $\lambda_{1}$ changes little with the change of constant term and inflation.

\section{Conclusions}

This paper estimates information update frequencies in China, the United States, and Eurozone based on epidemiology model. The estimation of information update frequency benefits the management of inflation persistence and inflation expectations because it is useful in grasp the moment of monetary and fiscal policy and information announcement. Therefore, the investigation of information update frequency is expected to improve the inflation and expectation management, and enhance assessment reliability and communication effectiveness of central banks. Our analysis demonstrates that the integrated information update frequency in China, the United States and Eurozone is much lower than once a quarter, indicating the slow spread of information and the induced different information sets which is exactly an essential causation of heterogeneous inflation expectations. In addition, the tardiness of information spread results in a continuous effect on inflation, which is a vital cause of inflation persistence. For specific district, the information update frequency in China is the highest, Eurozone is lower, and the United States is the lowest. The significantly different information dissemination speed should be attributed to economic development and national characteristics.

\section{References}

[1] Carroll C.D.2003, "Macroeconomic expectations of households and professional forecasters" The Quarterly Journal of Economics, 118, pp. 269-298.

[2] Doepke J, Dovern J, Fritsche U, Slacalek J. 2008, “The dynamics of European inflation expectations". BE Journal of Macroeconomics. 8, Article 12.

[3] Dovern J. and Doepke J., 2008, “The dynamics of European inflation expectations" The B.E. Journal of Macroeconomics. 
[4] Handjiyska B., 2004, "Adjustment of household inflation expectations in five OECD countries" mimeo, Johns Hopkins University.

[5] Gomes O., 2012, "Transitional dynamics in sticky-information general equilibrium models". Computational Economics 39(4):387-407.

[6] Khan, H, and Zhu Z, 2002, "Estimates of the Sticky Information Phillips Curve for the United States, Canada, and the United Kingdom" Bank of Canada working paper 19.

[7] Kiley, M T., 2007. "A quantitative comparison of sticky-price and sticky-information models of price setting”. Journal of Money, Credit and Banking. 39(s1):101-125.

[8] Mankiw N. Gregory and Ricardo Reis, 2001, "Sticky Information: A model of Monetary Nonneutrality and Structural Slumps" National Bureau of Economic Research, working paper No.8614.

[9] Mankiw N. Gregory, Ricardo Reis, and Justin Wolfers, 2003, "Disagreement about Inflation Expectations" National Bureau of Economic Research Macroeconomics, 18, pp. 209-270.

[10] Mankiw N. Gregory and Ricardo Reis, 2010, "Imperfect Information and Aggregate Supply". National Bureau of Economic Research, No.w15773.

[11]Nunes R., 2009, “On the epidemiological microfoundations of sticky information”. Oxford Bulletin of Economics and Statistics 71(5):643-657.

[12]Reid M, 2015, "Inflation expectations of the inattentive general public". Economic Modeling 46:157-166.

[13]Wieland E., 2014, "Information Rigidity and State-Dependence of Inflation Expectations: New Evidence from the CESifo World Economic Survey".

[14]Xu, Y, Liu, Z, Jia, Z, Su, CW. 2017, “Is time-variant information stickiness state-dependent?”. Portuguese Economic Journal, 16(3), 1-19. 